\title{
Analysis of the Situation of Unmet Health Care Need Among Extremely Rare Disease of Gaucher
}

\section{Xinye Qi}

Harbin Medical University School of Health Management

Jiao Xu

Harbin Medical University School of Health Management

\section{Linghan Shan}

Harbin Medical University School of Health Management

Ye Li

Harbin Medical University School of Health Management

Yu Cui

Harbin Medical University School of Health Management

Huan Liu

Harbin Medical University School of Health Management

Kexin Wang

Harbin Medical University School of Health Management

\section{Lijun Gao}

Harbin Medical University School of Health Management

Zheng Kang

Harbin Medical University School of Health Management

Qunhong Wu ( $\nabla$ wuqunhong@163.com )

Harbin Medical University https://orcid.org/0000-0002-2873-5266

\section{Research}

Keywords: Gaucher disease, Medical service utilization, Cost of illness, Health status, Caregiver, Diagnoses

Posted Date: December 16th, 2020

DOI: https://doi.org/10.21203/rs.3.rs-127301/v1

License: (c) (i) This work is licensed under a Creative Commons Attribution 4.0 International License. Read Full License 
Version of Record: A version of this preprint was published at Orphanet Journal of Rare Diseases on August 11th, 2021. See the published version at https://doi.org/10.1186/s13023-021-01963-6. 


\section{Abstract}

\section{Background}

The diagnosis and health care of patients with rare diseases present a tremendous challenge worldwide. This study estimated the health service utilization, cost of illness, and patients with Gaucher disease (GD)'s/caregivers' health-related quality of life in China.

Method

An online retrospective survey of patients with GD and their caregivers was conducted during May-June 2018. Socio-demographic, health service utilization, disease-related expenses, social support, sleep quality (Pittsburgh Sleep Quality Index [PSQI]), and the Short Form Health Survey (SF-36) were investigated. Using self-reported information, we estimated the annual cost of illness, including direct medical, direct non-medical, and indirect medical costs.

Results

Forty patients and their 49 caregivers were surveyed. The patients' onset age of GD was $9.3 \pm 10.9$; their disease course was $3.5 \pm 3.1$ years. 21 (42.9\%) patients had $\geq 2$ caregivers, but 35 (71.4\%) caregivers reported have no experience as a caregiver. $79.6 \%$ caregivers have stopped working, and $87.8 \%$ changed weekly working schedule. Before final diagnosis, patients visited 3.9 $\pm 3.1(\max =20)$ hospitals and took $1.2 \pm 1.7$ ( $\max =6.6$ ) years for confirmed diagnosis. On average, $5.0 \pm 9.6$ misdiagnoses occurred, and the per-patient diagnoses cost was USD (\$) 7,576. After GD confirmation, $8(16.3 \%)$ patients received no treatment, 40 (81.6\%) received pharmacotherapy, 10 (20.4\%) received surgery, $38(77.6 \%)$ received outpatient service (8.8 \pm 9.1 times/annually), and 37 (77.5\%) received inpatient service $(4.0 \pm 3.5$ times/annually). Annual per-patient cost was USD (\$) 49,925 (95\% confidence interval: $29,178,70,672)$. Average direct medical cost was $\$ 41,816$, including pharmaceutical $(\$ 29,908)$, inpatient $(\$ 7,451)$, and outpatient $(\$ 1,838)$. Productivity loss per-caregiver was $\$ 1,980$, and their Zarit Burden Inventory score was moderate-severe (48.6 \pm 19.6$)$. Both patients/caregivers reported lower social support (32.4 \pm 7.4 , $34.9 \pm 7.6)$, two times higher PSQI $(7.9 \pm 2.9,8.7 \pm 3.6)$, and half lower SF-36 $(41.3 \pm 18.6,46.5 \pm 19.3)$ than those reported for healthy Chinese individuals.

\section{Conclusion}

This study finds out that fill the unmet need for extremely rare diseases is very challenging. The high misdiagnosis rate, together with delayed diagnosis, substantial costs, and deteriorated health-related quality of life of GD patients as well as their heavy care burden, calls for extreme attention from policymakers in China. Further efforts of government and society are urgently demanded, including pharmaceutical reimbursement, screening newborns, developing precise diagnostic tools, and training doctors. 


\section{Background}

Gaucher disease (GD), an ultra-rare multi-organ involvement, inherited recessive enzyme deficiency[1, 2], is slowly progressing. Its standardized incidence and prevalence among the general population worldwide vary from 0.30 to 5.80 per 100,000 population, respectively; however, the initial estimate was 0.25 to 1.24 per 100,000 population $[3,4]$ with hundreds of patients diagnosed with GD in China. Accompanying symptoms of GD include anemia, thrombocytopenia, splenomegaly, hepatomegaly, and bone involvement[5], which often cause significant impairs to their health and the quality of life. And once diagnosed, it ought to be managed with enzyme replacement therapy[6, 7], but results in enormous expenses.

The World Health Organization has emphasized the need for urgent action to diagnose and treat people with rare diseases[8]. However, the diagnosis and treatment of rare diseases in China is still at a preliminary stage. Definitive GD diagnosis in China is difficult, especially with the high phenotypic heterogeneity of $\mathrm{GD}[9]$. Several studies have explored the length of time required for diagnosing rare diseases[10, 11]. A long duration is often required before a correct diagnosis or treatment, which implies considerable discomfort for the patients with rare diseases, such as GD, and their families. To the best of our knowledge, few studies have focused on health service utilization of GD, including the diagnosis[12]. Therefore, it is essential to find out the real situation and unmet health needs of patients with GD.

Currently, the effective therapy for GD patients, such as enzyme replacement therapy and substrate reduction therapy, that must be administered continually, are extremely costly for patients and caregivers $[13,14]$. Further, caregivers may experience workdays loss, absenteeism, and job changes while caring for their patients. Measuring the economic cost of illness can provide better information to policy makers to develop more targeted interventions to GD at various levels of health care system[15]. By measuring the economic and care burdens of diseases to the society will facilitate a prioritized healthcare policies and strategies[1]. However, evidence on the financial burden (e.g., direct medical costs, direct nonmedical costs, and indirect costs) associated with GD in China is limited[16, 17]. Extensive health care needs and frequent medical care and expenses are associated with the economic burden of patients and caregivers[18]. Hence, it is essential to identify unmet gap of patients with GD in China[19].

This study aimed to assess the health service utilization, cost of illness, and health-related quality of life of patients with GD, as well as the quality of life of their caregivers.

\section{Results}

\section{Socio-Demographic Characteristics}

Characteristics of enrolled patients with GD, families, and caregivers are shown in Table 1, which shown GD often occur in child and adolescents. Nineteen (38.9\%) of the patients were aged $0-4$ years. And $77.5 \%$ of patients with GD were $<15$ years old. GD treatment differs according to the disease classification, although in $40.8 \%$ of respondents, the exact type was unclear. The age of GD onset was 
$9.3 \pm 10.9$; disease course from symptom onset of GD ranged from 0.3 to $12.1(3.5 \pm 3.1)$ years. In total, $42.9 \%$ of patients had $\geq 2$ caregiver. 
Table 1

Characteristics of enrolled patients with Gaucher disease, families, and caregivers.

\begin{tabular}{|c|c|c|}
\hline Items & Sample (n) & Proportion (\%) \\
\hline \multicolumn{3}{|c|}{ Gaucher disease patients' characteristics } \\
\hline \multicolumn{3}{|l|}{ Sex } \\
\hline Male & 25 & 51.0 \\
\hline Female & 24 & 49.0 \\
\hline \multicolumn{3}{|c|}{ Age group (mean age at survey) in years } \\
\hline $0-4$ & 19 & 38.9 \\
\hline $5-7$ & 5 & 10.2 \\
\hline $8-12$ & 12 & 24.5 \\
\hline $13-14$ & 2 & 4.1 \\
\hline$\geq 15$ & 11 & 22.5 \\
\hline \multicolumn{3}{|c|}{ Age at onset, years } \\
\hline Mean \pm SD & \multicolumn{2}{|l|}{$9.3 \pm 10.69$} \\
\hline Max & \multicolumn{2}{|l|}{44} \\
\hline Min & \multicolumn{2}{|l|}{1} \\
\hline \multicolumn{3}{|c|}{ Disease course from symptom onset, days } \\
\hline Mean \pm SD & \multicolumn{2}{|l|}{$3.5 \pm 3.1$} \\
\hline Max & \multicolumn{2}{|l|}{12.1} \\
\hline Min & \multicolumn{2}{|l|}{0.3} \\
\hline Median & \multicolumn{2}{|l|}{2.0} \\
\hline \multicolumn{3}{|c|}{ Types of Gaucher disease (GD) } \\
\hline Type I & 20 & 40.8 \\
\hline Type II & 5 & 10.2 \\
\hline Type III & 4 & 8.2 \\
\hline Not clear & 20 & 40.8 \\
\hline \multicolumn{3}{|c|}{ Number of caregivers } \\
\hline 1 & 28 & 57.1 \\
\hline
\end{tabular}




\begin{tabular}{|c|c|c|}
\hline Items & Sample (n) & Proportion (\%) \\
\hline$\geq 2$ & 21 & 42.9 \\
\hline \multicolumn{3}{|c|}{ Family characteristics } \\
\hline \multicolumn{3}{|c|}{ Family history with GD } \\
\hline No & 40 & 81.6 \\
\hline Yes & 9 & 18.4 \\
\hline \multicolumn{3}{|c|}{ Current residence } \\
\hline Urban & 19 & 38.8 \\
\hline Rural & 30 & 61.2 \\
\hline \multicolumn{3}{|c|}{ Living on minimum subsistence allowance or relatives' relief } \\
\hline No & 32 & 65.3 \\
\hline Yes & 17 & 34.7 \\
\hline \multicolumn{3}{|c|}{ Member with chronic disease } \\
\hline No & 30 & 61.2 \\
\hline Yes & 19 & 38.3 \\
\hline \multicolumn{3}{|c|}{ Member $>60$ years of age } \\
\hline No & 7 & 14.3 \\
\hline Yes & 42 & 85.7 \\
\hline \multicolumn{3}{|c|}{ Member $<5$ years of age } \\
\hline No & 26 & 53.1 \\
\hline Yes & 23 & 46.9 \\
\hline \multicolumn{3}{|c|}{ GD caregiver's characteristics } \\
\hline \multicolumn{3}{|l|}{ Sex } \\
\hline Male & 13 & 26.5 \\
\hline Female & 36 & 73.5 \\
\hline Age & $34.8 \pm 10.4$ & \\
\hline \multicolumn{3}{|l|}{ Education } \\
\hline Primary School & 4 & 8.2 \\
\hline
\end{tabular}




\begin{tabular}{|c|c|c|}
\hline Items & Sample (n) & Proportion (\%) \\
\hline Middle or high school & 30 & 61.2 \\
\hline College & 15 & 30.6 \\
\hline \multicolumn{3}{|l|}{ Daily care time } \\
\hline$<6 \mathrm{~h}$ & 9 & 18.4 \\
\hline $6-12 \mathrm{~h}$ & 17 & 34.7 \\
\hline $12-18 \mathrm{~h}$ & 2 & 4.1 \\
\hline $18-24 \mathrm{~h}$ & 21 & 42.9 \\
\hline \multicolumn{3}{|c|}{ Experience being caregiver } \\
\hline No & 35 & 71.4 \\
\hline Yes & 14 & 28.6 \\
\hline \multicolumn{3}{|c|}{ Main caregiver stopped working because of patients' GD } \\
\hline No & 10 & 20.4 \\
\hline Yes & 39 & 79.6 \\
\hline \multicolumn{3}{|c|}{ Change of weekly working time because of patient's GD } \\
\hline No & 6 & 12.2 \\
\hline Yes & 43 & 87.8 \\
\hline \multicolumn{3}{|l|}{ ZBI } \\
\hline \multicolumn{3}{|c|}{ Maximum scores, 88 points } \\
\hline No & 30.6 & \\
\hline Yes & 69.4 & \\
\hline Mean \pm SD & $48.57 \pm 19.57$ & \\
\hline
\end{tabular}

Among patients' families, $18.4 \%$ had a family history of GD and $85.7 \%$ had family members aged > 60 years. Among the 49 caregivers, $81.6 \%$ reported caring for the patients for $>6 \mathrm{~h}$ daily and $71.4 \%$ having no caregiving experience. Further, $79.6 \%$ and $87.8 \%$ of caregivers stopped working and absenteeism. 79.6\% changed their weekly working schedule. The Zarit Burden Inventory (ZBI) score, indicating the burden of the caregivers, was from moderate to severe (48.57 \pm 19.57$)$. 
The profile of health service utilization of patients with GD are shown in Table 2. Patients' original reasons for visiting the doctors included enlarged liver and spleen (71.4\%), normocytic anemia (36.7\%), dyskinesia (12.2\%), and osteopenia (8.2\%). Among all surveyed patients, the two most frequent symptoms were hepatosplenomegaly (85.7\%) and normocytic anemia (73.5\%). Many patients (43.5\%) reported that they had to travel to the tertiary hospitals in other provinces to get confirmed diagnosed. Among 49 patients, $77.6 \%$ received outpatient service and $77.5 \%$ received inpatient service. 
Table 2

Descriptive analysis of the utilization of health service, including the diagnosis and treatment $(n=49)$.

Items

Sample (n)

Proportion (\%)

The original reason for visiting the doctors

Osteopenia

Normocytic anemia

Dyskinesia

Obviously enlarged liver and spleen

Top current symptoms

Hepatosplenomegaly

Normocytic anemia

Bone pain or other bone symptoms

Growth retardation

Nervous system involvement

Gastrointestinal symptoms

Types of medical institutions frequently visited

Clinics/community health service centers

County-level medical institutions

Municipal medical institutions

Provincial medical institutions in the province

Provincial medical institutions in other provinces

None

In the past year, outpatient visit for GD

No

Yes

Mean \pm SD

In the past year, inpatient visit for GD

No

Yes
4

18

6

35

42

36

17

33

10

9

1

4

11

10

20

3

11

38

$8.8 \pm 9.1$ $\begin{array}{lll}8.2 & 2.3 & 19.6\end{array}$

$\begin{array}{lll}36.7 & 23.4 \quad 50.2\end{array}$

$12.2 \quad 3.1 \quad 21.4$

$\begin{array}{lll}71.4 & 56.7 & 83.4\end{array}$ 


\begin{tabular}{|c|c|c|c|c|}
\hline Items & Sample (n) & \multicolumn{2}{|c|}{ Proportion (\%) } & \\
\hline Mean \pm SD & $4.0 \pm 3.5$ & & & \\
\hline \multicolumn{5}{|l|}{ Traffic time } \\
\hline$<5 \mathrm{~h}$ & 24 & 49.0 & 34.4 & 63.7 \\
\hline$\geq 5 \mathrm{~h}$ & 25 & 51.0 & 36.3 & 65.6 \\
\hline \multicolumn{5}{|c|}{$\begin{array}{l}\text { Number of hospitals visited for GD to confirm GD } \\
\text { diagnosis }\end{array}$} \\
\hline Median & 3.0 & & & \\
\hline Mean \pm SD & $3.9 \pm 3.1$ & & & \\
\hline Max & 20 & & & \\
\hline \multicolumn{5}{|c|}{ Total cost for GD diagnosis } \\
\hline Median & 7575.8 & & & \\
\hline Mean \pm SD & $\begin{array}{l}15249.8 \pm \\
22854.3\end{array}$ & & 8685.3 & 21814.4 \\
\hline \multicolumn{5}{|c|}{ Length of misdiagnosis (days) } \\
\hline $0-60$ & 14 & 28.6 & 16.6 & 43.3 \\
\hline $60-120$ & 9 & 18.4 & 8.8 & 32.0 \\
\hline $120-180$ & 4 & 8.2 & 2.3 & 19.6 \\
\hline$\geq 180$ & 22 & 44.9 & 30.7 & 59.8 \\
\hline Mean $\pm S D$, years & $1.2 \pm 1.7$ & & & \\
\hline \multicolumn{5}{|c|}{ Duration of GD final confirmed diagnosed, years } \\
\hline Mean \pm SD & $1.2 \pm 1.7$ & & & \\
\hline Median & 0.4 & & & \\
\hline Max & 6.6 & & & \\
\hline \multicolumn{5}{|l|}{ GD Misdiagnosis } \\
\hline No & 20 & 40.8 & 27.0 & 55.8 \\
\hline Yes & 29 & 59.2 & 44.2 & 73.0 \\
\hline \multicolumn{5}{|c|}{ Number of GD misdiagnosis } \\
\hline Median & 2.0 & & & \\
\hline
\end{tabular}

SD = standard deviation; GD = Gaucher disease. 


\begin{tabular}{|c|c|c|c|c|}
\hline Items & Sample (n) & \multicolumn{3}{|c|}{ Proportion (\%) } \\
\hline \multicolumn{5}{|c|}{ Before being correctly diagnosed with GD, $(n=29)$} \\
\hline Unexplained splenomegaly & 19 & 65.5 & 48.2 & 82.8 \\
\hline Hypersplenism & 13 & 44.8 & 26.5 & 64.3 \\
\hline Hemophilia & 3 & 10.3 & 2.2 & 27.4 \\
\hline \multicolumn{5}{|c|}{ Therapy after diagnosis with GD } \\
\hline No & 8 & 16.3 & 7.3 & 29.7 \\
\hline Yes & 41 & 83.7 & 70.3 & 92.7 \\
\hline \multicolumn{5}{|l|}{ Surgery, splenectomy } \\
\hline No & 39 & 79.6 & 65.7 & 89.8 \\
\hline Yes & 10 & 20.4 & 10.2 & 34.3 \\
\hline \multicolumn{5}{|c|}{ Pharmacotherapy after diagnosis with GD } \\
\hline No & 9 & 18.4 & 8.8 & 32.0 \\
\hline Yes & 40 & 81.6 & 68.0 & 91.2 \\
\hline \multicolumn{5}{|c|}{ Purchased medicine at medical institutions, $(n=40)$} \\
\hline No & 4 & 10.0 & 2.8 & 23.7 \\
\hline Yes & 36 & 90.0 & 76.3 & 97.2 \\
\hline \multicolumn{5}{|c|}{$\begin{array}{l}\text { Purchased medicine at social pharmacy or } \\
\text { overseas, }(n=40)\end{array}$} \\
\hline No & 9 & 22.5 & 10.8 & 38.5 \\
\hline Yes & 31 & 77.5 & 61.6 & 89.2 \\
\hline \multicolumn{5}{|c|}{ Taking medication as prescribed, $(n=40)$} \\
\hline No & 14 & 35.0 & 20.6 & 51.7 \\
\hline Yes & 26 & 65.0 & 48.3 & 79.4 \\
\hline
\end{tabular}

Hardly recognized by many doctors, the patients visited $3.9 \pm 3.1$ hospitals, and it took $1.2 \pm 1.7$ (median $=0.4$, $\max =6.6$ ) years for the diagnosis to be confirmed. The total cost for GD diagnosis was USD (\$) 7,575.8 (median); $59.2 \%$ of patients experienced $\geq 1$ misdiagnosis, with a mean of 5.0 ( $S D=9.6$, median $=2.0$ ). Before the correct diagnosis, most patients were misdiagnosed with unexplained splenomegaly 
(65.5\%), hypersplenism (44.8\%), and hemophilia (10.2\%). Eight (16.3\%) patients received no health service following GD diagnosis. Ten patients underwent surgery $(20.4 \%$; splenectomy $=9$; hematopoietic stem cell transplantation $=1)$. The remaining $40(81.6 \%)$ received pharmacotherapy, among whom 14 (35.0\%) had not used medications as prescribed, 27 (67.5\%) reported using imported drugs, 9 took imiglucerase (the medicine used treatment of GD), and 5 were still using imiglucerase from the onset of GD diagnosis; all 49 (100\%) agreed that the high price of medicine led to the failure of compliance with the doctor's prescription. Furthermore, $36(90.0 \%)$ reported purchasing their medications at medical institutions or pharmacy, while 31 (71.5\%) purchase from overseas.

Table 3 shows the caregivers' perception on GD treatment. Most (89.8\%) caregivers perceived that the availability of therapeutic drugs was problematic. All (100\%) caregivers reported their inability to afford therapeutic drugs. 48 (98.0\%) Caregivers reported have no knowledge of GD. Most (96.0\%) caregivers felt difficulty in obtaining diagnosis information. The top two problems confronting the caregivers during GD treatment were "high treatment cost" (95.8\%), and "far away from hospitals" (75.0\%). Up to $79.6 \%$ of 49 caregivers were extremely unconfident about future treatment. 
Table 3

Caregiver' perception of Gaucher disease treatment $(n=49)$.

\begin{tabular}{|c|c|c|c|c|}
\hline \multirow[t]{2}{*}{ Variables } & \multirow[t]{2}{*}{ Samples ( $\mathrm{n}$ ) } & \multicolumn{3}{|c|}{ Proportion(\%) } \\
\hline & & & Low limit & Upper limit \\
\hline \multicolumn{5}{|c|}{ Availability of therapeutic drugs } \\
\hline Very insufficient & 19 & 38.8 & 25.2 & 53.8 \\
\hline Insufficient & 9 & 18.4 & 8.8 & 32.0 \\
\hline Medium & 16 & 32.7 & 20.0 & 47.5 \\
\hline Sufficient & 5 & 10.2 & 3.4 & 22.2 \\
\hline \multicolumn{5}{|c|}{ Affordability of therapeutic drugs } \\
\hline Very unaffordable & 7 & 14.3 & 5.9 & 27.2 \\
\hline Unaffordable & 35 & 71.4 & 56.7 & 83.4 \\
\hline Medium & 7 & 14.3 & 5.9 & 27.2 \\
\hline \multicolumn{5}{|l|}{ Knowledge of GD } \\
\hline No & 48 & 98.0 & & \\
\hline Yes & 1 & 2.0 & & \\
\hline \multicolumn{5}{|c|}{ The difficulty to get diagnosis information } \\
\hline Difficult & 47 & 95.9 & & \\
\hline Not difficult & 2 & 4.1 & & \\
\hline \multicolumn{5}{|c|}{ Feel of the difficult to treatment } \\
\hline No & - & - & & \\
\hline Yes & 49 & 100.0 & & \\
\hline \multicolumn{5}{|c|}{ Difficulties during GD treatment } \\
\hline \multicolumn{5}{|c|}{ Far away from hospital } \\
\hline No & 12 & 25.0 & 13.6 & 39.6 \\
\hline Yes & 37 & 75.0 & 60.4 & 86.4 \\
\hline \multicolumn{5}{|l|}{ High treatment cost } \\
\hline No & 2 & 4.1 & 0.5 & 14.25 \\
\hline Yes & 47 & 95.9 & 85.8 & 99.5 \\
\hline
\end{tabular}




\begin{tabular}{|lllll|}
\hline Variables & Samples $(\mathbf{n})$ & \multicolumn{3}{l|}{ Proportion(\%) } \\
\hline No & 10 & 20.4 & 10.2 & 34.3 \\
\hline Yes & 39 & 79.6 & 65.7 & 89.8 \\
\hline
\end{tabular}

\section{Cost of Illness}

The cost of illness of patients with GD is shown in Table 4 and Fig. 1. In total, the mean annual economic burden of GD was estimated at $\$ 49,924$. The mean direct medical costs of GD estimated at $\$ 41,816.2$ (83.8\% of total costs) mainly comprised of taking medicine at home (59.9\% of total costs), inpatient treatment (14.9\%), outpatient treatment (3.7\%), and medical tests (3.4\%). 
Table 4

Average annual cost of illness due to Gaucher disease (GD) in China $(\$, n=41)$

\begin{tabular}{|c|c|c|c|c|}
\hline & \multirow[t]{2}{*}{$\begin{array}{l}\text { Mean annual } \\
\text { costs }\end{array}$} & \multicolumn{2}{|l|}{$95 \% \mathrm{Cl}$} & \multirow[t]{2}{*}{$\begin{array}{l}\text { Ratio of COI } \\
\text { (\%) }\end{array}$} \\
\hline & & $\begin{array}{l}\text { Low } \\
\text { limit }\end{array}$ & $\begin{array}{l}\text { Upper } \\
\text { limit }\end{array}$ & \\
\hline Direct medical cost & $\begin{array}{l}41816.2 \pm \\
65745.4\end{array}$ & 21064.4 & 62568.0 & 83.76 \\
\hline Outpatient medical treatment & $1838.1 \pm 3029.4$ & 881.9 & 2794.4 & 3.68 \\
\hline Inpatient medical treatment & $7451.2 \pm 10392.2$ & 4171.1 & 10731.4 & 14.92 \\
\hline Pharmaceutical treatment & $\begin{array}{l}29907.6 \pm \\
63861.1\end{array}$ & 9750.6 & 50064.7 & 59.91 \\
\hline Medical tests & $1675.9 \pm 3207.2$ & 663.6 & 2688.2 & 3.36 \\
\hline Formal care & $580.6 \pm 817.7$ & 322.5 & 838.7 & 1.16 \\
\hline Other cost/expenditures & $362.7 \pm 654.3$ & 156.2 & 569.3 & 0.73 \\
\hline Other cost/expenditures of outpatient & $88.1 \pm 159.7$ & 37.7 & 138.5 & 0.18 \\
\hline Other cost/expenditures of inpatient & $274.6 \pm 633.0$ & 74.8 & 474.5 & 0.55 \\
\hline Direct non-medical cost & $4974.4 \pm 4675.9$ & 3498.5 & 6450.3 & 9.96 \\
\hline Accommodation & $1245.0 \pm 1711.2$ & 704.9 & 1785.1 & 2.49 \\
\hline Accommodation of outpatient & $440.3 \pm 597.8$ & 251.6 & 629.0 & 0.88 \\
\hline Accommodation of inpatient & $804.7 \pm 1562.6$ & 311.5 & 1297.9 & 1.61 \\
\hline Transportation & $819.9 \pm 841.5$ & 554.3 & 1085.5 & 1.64 \\
\hline Transportation of outpatient & $581.8 \pm 685.9$ & 365.3 & 798.3 & 1.17 \\
\hline Transportation of inpatient & $238.0 \pm 376.3$ & 119.3 & 356.8 & 0.48 \\
\hline Meals & $749.8 \pm 874.9$ & 473.7 & 1026.0 & 1.50 \\
\hline Meals of outpatient & $277.3 \pm 356.2$ & 164.8 & 389.7 & 0.56 \\
\hline Meals of inpatient & $472.6 \pm 740.1$ & 239.0 & 706.2 & 0.95 \\
\hline Costs for artificial nutrition & $1340.0 \pm 2796.6$ & 457.3 & 2222.7 & 2.68 \\
\hline \multicolumn{5}{|c|}{ Because of rounding, percentage might not add up to exactly $100 \%$. } \\
\hline \multicolumn{5}{|c|}{$\begin{array}{l}\text { * The medical costs were converted to US Dollar using Purchasing Power Parities (PPP) in the study } \\
\text { years (2018) (OECD National Accounts Statistics: PPP https://data.oecd.org/conversion/purchasing- } \\
\text { power-parities-ppp.htm\#indicator-chart). }\end{array}$} \\
\hline $\mathrm{COI}=$ cost of illness. & & & & \\
\hline
\end{tabular}




\begin{tabular}{|c|c|c|c|c|}
\hline & $\begin{array}{l}\text { Mean annual } \\
\text { costs }\end{array}$ & $95 \% \mathrm{Cl}$ & & $\begin{array}{l}\text { Ratio of COI } \\
\text { (\%) }\end{array}$ \\
\hline Other cost/expenditures & $819.7 \pm 929.0$ & 526.4 & 1112.9 & 1.64 \\
\hline Direct cost & $\begin{array}{l}46790.6 \pm \\
65714.2\end{array}$ & 26048.6 & 67532.5 & 93.72 \\
\hline Indirect cost & $3134.2 \pm 2556.4$ & 2327.3 & 3941.1 & 6.28 \\
\hline Annual indirect cost of treatment & $1153.7 \pm 1046.9$ & 823.3 & 1484.2 & 2.31 \\
\hline $\begin{array}{l}\text { Productivity loss to caregiver due to } \\
\text { caring }\end{array}$ & $1980.4 \pm 1962.8$ & 1360.9 & 2600.0 & 3.97 \\
\hline Cost of illness (COI) & $\begin{array}{l}49924.7 \pm \\
65729.9\end{array}$ & 29177.8 & 70671.6 & 100.00 \\
\hline \multicolumn{5}{|c|}{ Because of rounding, percentage might not add up to exactly $100 \%$. } \\
\hline \multicolumn{5}{|c|}{$\begin{array}{l}\text { * The medical costs were converted to US Dollar using Purchasing Power Parities (PPP) in the study } \\
\text { years (2018) (OECD National Accounts Statistics: PPP https://data.oecd.org/conversion/purchasing } \\
\text { power-parities-ppp.htm\#indicator-chart). }\end{array}$} \\
\hline
\end{tabular}

The average annual direct non-medical costs added up to $\$ 4,974.4$ (10.0\% of total costs). With both direct medical and non-medical costs, the annual direct cost was estimated at $\$ 46,790.6$. The indirect costs for GD primarily originated from the productivity loss to the caregivers while caring for patients with GD (4.0\% of total costs). Accordingly, the total annual indirect costs were estimated at $\$ 3,134.2$.

\section{Social Support and Health-Related Quality of Life of Patients and Their Caregivers}

The total Social Support Rating Scale (SSRS), Pittsburgh Sleep Quality Index (PSQI), and Short Form Health Survey (SF-36) scores for patients with GD, their caregivers, and norms of healthy Chinese people are shown in Table 5. Patients with GD and their caregivers reported mean SSRS scores of $25.3 \pm 5.7$ and $26.1 \pm 5.6$, respectively. Both were remarkably lower than the SSRS score $(40.5 \pm 6.8)$ for healthy Chinese people (all p-value $<0.05$ ). The mean PSQI scores for patients and caregivers scores were $7.9 \pm 2.9$ and $8.7 \pm 3.6$, respectively. Patients with GD and their caregivers reported two times higher PSQI scores than the normal values for healthy Chinese people (3.9 \pm 2.5$)$ (all p-value $<0.05)$. Overall, $16(32.7 \%)$ of caregivers rated sleep problems using PSQI dimensions. All the seven PSQI dimension scores for the caregivers were higher than the normal values for healthy Chinese people (all $p$-value $<0.05$ ). 
Table 5

Psychosocial burden of Gaucher disease on the caregivers.

$\begin{array}{lllll}\begin{array}{l}\text { Patients } \\ (n=30)\end{array} & \begin{array}{l}\text { Caregivers } \\ (n=49)\end{array} & \begin{array}{l}\text { Norm of healthy } \\ \text { Chinese people }\end{array} & P^{a} & p^{b}\end{array}$

\section{SSRS $^{\mathrm{C}}$}

Maximum score, 40 points

\begin{tabular}{|llllll|}
\hline Objective support & $8.2 \pm 2.5$ & $8.2 \pm 2.3$ & $9.1 \pm 2.9$ & 0.059 & 0.009 \\
\hline Subjective support & $17.6 \pm 5.0$ & $19.9 \pm 4.9$ & $23.5 \pm 4.3$ & 0.000 & 0.000 \\
\hline Utilization of support & $6.6 \pm 1.8$ & $6.7 \pm 1.9$ & $7.8 \pm 2.0$ & 0.001 & 0.000 \\
\hline Mean \pm SD & $32.4 \pm 7.4$ & $34.9 \pm 7.6$ & $40.5 \pm 6.8$ & 0.000 & 0.000
\end{tabular}

PSQI $^{d}$

Maximum score, 21 points

\begin{tabular}{llllll|} 
Not good & $6(20.0)$ & $16(32.7)$ & & & \\
Good & $24(80.0)$ & $33(67.3)$ & & 0.000 & 0.000 \\
\hline Mean \pm SD & $7.9 \pm 2.9$ & $8.7 \pm 3.6$ & $3.9 \pm 2.5$ & 0.000 & 0.000 \\
\hline Subjective sleep quality & $1.57 \pm 0.97$ & $1.71 \pm 0.89$ & $0.63 \pm 0.68$ & 0.000 & 0.000 \\
\hline Sleep latency & $1.77 \pm 0.77$ & $1.59 \pm 0.91$ & $0.70 \pm 0.86$ & 0.000 & 0.000 \\
\hline Sleep duration & $0.87 \pm 1.01$ & $1.24 \pm 0.97$ & $0.70 \pm 0.58$ & 0.000 & 0.000 \\
\hline Habitual sleep efficiency & $0.27 \pm 0.69$ & $0.63 \pm 0.86$ & $0.15 \pm 0.47$ & 0.000 & 0.000 \\
\hline Step disturbance & $1.73 \pm 0.52$ & $1.61 \pm 0.57$ & $0.90 \pm 0.44$ & - & 0.000 \\
\hline Use of sleeping medication & 0.00 & $0.08 \pm 0.34$ & $0.06 \pm 0.24$ & &
\end{tabular}

a Patients vs. normal values for healthy Chinese.

${ }^{b}$ Caregivers vs. normal values for healthy Chinese.

${ }^{\mathrm{c}} \mathrm{N}=3342,[71]$

${ }^{d} \mathrm{~N}=112,[72]$

${ }^{e} \mathrm{~N}=17754,[73]$

${ }^{\mathrm{f}} \mathrm{N}$ of patients $>=15$ is 11

SSRS = Social Support Rating Scale; PSQI = Pittsburgh Sleep Quality Index; SF-36 = Medical Outcomes Study 36-item Short Form; SD = standard deviation. 


\begin{tabular}{|c|c|c|c|c|c|}
\hline & $\begin{array}{l}\text { Patients } \\
(n=30)\end{array}$ & $\begin{array}{l}\text { Caregivers } \\
(n=49)\end{array}$ & $\begin{array}{l}\text { Norm of healthy } \\
\text { Chinese people }\end{array}$ & $\mathbf{P}^{a}$ & $p^{b}$ \\
\hline Daytime dysfunction & $1.67 \pm 1.03$ & $1.82 \pm 1.11$ & $0.73 \pm 0.83$ & 0.000 & 0.000 \\
\hline \multicolumn{6}{|l|}{ SF-36e,f } \\
\hline \multicolumn{6}{|l|}{$\begin{array}{l}\text { Maximum score, } 100 \text { points } \\
\text { for each item }\end{array}$} \\
\hline Total score & $41.3 \pm 18.6$ & $46.5 \pm 19.3$ & & & \\
\hline $\begin{array}{l}\text { Physical Component } \\
\text { Summary (PCS) }\end{array}$ & $39.4 \pm 22.4$ & $47.6 \pm 23.0$ & $77.5 \pm 16.0$ & 0.000 & 0.000 \\
\hline $\begin{array}{l}\text { Mental Component } \\
\text { Summary (MCS) }\end{array}$ & $43.2 \pm 16.1$ & $45.4 \pm 20.4$ & $71.3 \pm 17.9$ & 0.000 & 0.000 \\
\hline Physical functioning (PF) & $63.2 \pm 20.2$ & $63.8 \pm 30.2$ & $87.9 \pm 17.0$ & 0.000 & 0.000 \\
\hline Role physical (RP) & $13.6 \pm 32.3$ & $27.6 \pm 43.1$ & $77.5 \pm 34.9$ & 0.000 & 0.000 \\
\hline Bodily pain (BP) & $51.8 \pm 23.3$ & $60.3 \pm 26.3$ & $82.2 \pm 17.0$ & 0.000 & 0.000 \\
\hline General health $(\mathrm{GH})$ & $29.0 \pm 25.9$ & $38.9 \pm 21.9$ & $62.5 \pm 17.9$ & 0.000 & 0.000 \\
\hline Vitality (VT) & $42.7 \pm 16.5$ & $45.3 \pm 18.6$ & $68.2 \pm 17.6$ & 0.000 & 0.000 \\
\hline Social functioning (SF) & $71.6 \pm 26.9$ & $67.6 \pm 30.0$ & $80.7 \pm 20.0$ & 0.013 & 0.004 \\
\hline Role emotional (RE) & $6.1 \pm 20.1$ & $20.4 \pm 37.2$ & $67.9 \pm 39.4$ & 0.000 & 0.000 \\
\hline Mental health (MH) & $52.4 \pm 17.1$ & $48.3 \pm 16.0$ & $68.5 \pm 16.9$ & 0.000 & 0.000 \\
\hline \multicolumn{6}{|c|}{ a Patients vs. normal values for healthy Chinese. } \\
\hline \multicolumn{6}{|c|}{ b Caregivers vs. normal values for healthy Chinese. } \\
\hline \multicolumn{6}{|l|}{${ }^{c} N=3342,[71]$} \\
\hline \multicolumn{6}{|l|}{${ }^{d} N=112,[72]$} \\
\hline \multicolumn{6}{|l|}{ e $N=17754,[73]$} \\
\hline \multicolumn{6}{|l|}{${ }^{f} \mathrm{~N}$ of patients $>=15$ is 11} \\
\hline $\begin{array}{l}\text { SSRS = Social Support Rati } \\
\text { Study 36-item Short Form; }\end{array}$ & $\begin{array}{l}\text { Scale; PSQI = } \\
=\text { standard de }\end{array}$ & $\begin{array}{l}\text { ttsburgh Sle } \\
\text { ation. }\end{array}$ & Quality Index; SF-3 & dical C & comes \\
\hline
\end{tabular}

Besides, the health-related quality of life of the patients with GD and caregivers was assessed. Patients $(39.4 \pm 22.4)$ and caregivers $(47.6 \pm 23.0)$ reported half lower Physical Component Summary than the normal values for healthy Chinese people $(77.5 \pm 16.0$, all p-value $<0.05)$. Further, Mental Component 
Summary in both patients $(43.2 \pm 16.1)$ and caregivers $(45.4 \pm 20.4)$ was significantly half lower than the normal values in healthy Chinese people $(71.3 \pm 17.9$, all $p$-value $<0.05)$.

\section{Discussion}

There is a dearth of evidence on the health service utilization and economic burden of rare disease patients with GD in China. In this study, we performed a comprehensive, analysis and identified a wide range of unmet needs and problems of patients with GD in their health service utilization, cost of illness, and health-related quality of life associated with GD in China. Families of patients with GD often experienced delays in diagnosis and misdiagnosis, enormous economic cost, and caregiving burden. Lack of social support often resulted in deteriorated health related quality of life and other major health issues which deserve great attention of society.

Misdiagnosis or delayed diagnosis is especially detrimental to patients[20]. Although several publications have acknowledged that diagnostic delays or misdiagnosis often occurs in obtaining a definitive GD diagnosis [21], this study further quantified the exact time delay and difficulty in obtaining the correct diagnosis that occurred in $79.6 \%$ surveyed patients. $59.2 \%$ of them experienced misdiagnosis, of up to $5.0 \pm 9.6$ times. Besides, patients reported multiple referrals $(3.9 \pm 3.1)$ to different hospitals before their disease was accurately determined. Studies indicated the process of continually seeking diagnosis was a traumatic experience for patients with rare diseases[22]. Patients spent $1.2 \pm 1.7$ years to receive a definitive diagnosis since the onset of symptom, and $44.9 \%$ of 40 patients had lived with their rare condition for $>6$ months before accurate diagnosis. Due to the frequent misdiagnosis and delayed diagnosis, patients ended up paying $\$ 15,250$ for the final GD diagnoses. Davari $\mathrm{M}$ et al. have shown a patient misdiagnosed with GD had taken medications for ten years at the cost of $\$ 207,580[1]$. Thus, a rapid precise diagnosis of patients is essential for reducing unnecessary tests or costs[21, 23, 24], and preventing psychological stress for the family[25].

The main reason for the prolonged diagnostic delay most likely is insufficient knowledge on GD[26-28] by the medical community due to its low prevalence, extreme variations in clinical manifestations[23, 29], and severity of symptoms (e.g., bone pain/bone crisis, thrombocytopenia, and splenomegaly) [12, 21, 23]. Nevertheless, a survey revealed that only one of five hematologist-oncologist considers GD in the differential diagnosis of patients with a history of anemia, thrombocytopenia, hepatomegaly, splenomegaly, and bone pain. In this study, $79.6 \%$ of patients had visited doctors with obvious symptoms (osteopenia, normocytic anemia, dyskinesia, and obviously enlarged liver) in whom GD was not diagnosed in a timely manner. Therefore, establishing an information center of rare disease symptoms[30] and providing training on diagnostic methods and appropriate clinical guidelines to medical doctors are essential to effectively support early diagnosis of rare diseases. Besides, because most rare diseases are caused by DNA mutations or are recessive genetic diseases[31], family history and genetic screening could facilitate earlier diagnosis, while genetic testing can be used to confirm disease diagnosis[32]. Nine families reported a family history of the same disorder in this study, indicating a need for awareness of genetic disorders to highlight the importance and burden of genetic diseases. Therefore, 
newborn screening for disorders that meet the criteria for population screening[33], use of reliable diagnostic tools[1,34-36], raising of awareness on the early signs/symptoms[37] or less severe manifestation [21], and initiation of therapy early for rare diseases[30], are essential.

In particular, long-term treatment with regular monitoring for GD can optimize outcomes[38], alleviate fewer exacerbations[1], and reduce the incidence of complications[39]. A Gaucher outcome survey involved 1209 patients with GD reported the overall treatment $(1,209,73.4 \%)$ and different treatment rates in countries [the UK $(119,93.3 \%)$, Israel $(536,63.6 \%)$, the US $(380,82.6 \%)$, rest of the world $(174,69.5 \%)$ ] [40]. In this study, 8 of the 49 patients (16.3\%) were never treated, while $83.7 \%$ get treated, and $10(20.4 \%)$ of patients undergone splenectomy, which was higher than previous research $(8.7 \%-13.3 \%)[2,40]$. Besides, other studies also shown a significant proportion of patients (e.g., asymptomatic or mildly affected) never accessed medical attention or required treatment[41, 42]. In this study, even $20(40.8 \%)$ of patients did not clear the type of their GD. Maaswinkel Mooij et al.[43] found that no treatment for type 1 GD with enzyme replacement therapy can worsen the condition at any age in non-Jewish patients[44]. Besides, 4 of 9 patients who took imiglucerase interrupted their treatment in this study. However, Drelichman et al. emphasized the need to avoid interruption of medical treatment of patients with GD because of recurrent organomegaly, growth delays, and skeletal manifestations[45]. Furthermore, a previous study identified association of high immunoglobulin (Ig) A and IgG levels with long-term complications[46]. Therefore, long-term treatment and surveillance are required for improving the efficiency of GD management[47].

To estimate the annual cost of GD, we presented the core components of costs for health care services separately, from the payer' perspectives, excluding patients' out-of-pocket costs and informal care. The estimated annual per-patient cost of GD of $\$ 49,925$ (95\% confidence interval [CI]: $\$ 29,178, \$ 70,672$, which is 5.3 times of GDP per capita of China in 2018(\$9,377)[48]. The additional time spent by caregivers for providing care reflects an annual productivity loss of $\$ 1,980$ per patient. In contrast, a recent analysis using the human capital approach showed high costs [e.g., Splenectomy $(\$ 13,698)$, Bone complication $(\$ 10,002)$, Multiple complications $(\$ 10,615)$, and Malignancy $(\$ 73,057)]$ that generated much higher indirect costs than ours[49], whereas we calculated indirect costs with the actual wage of the caregivers. Besides, direct non-medical costs $(\$ 4,974)$, comprised those for accommodation, transportation, meals, and other expenditures, which accounted for $10.6 \%$ of direct costs; this indicated a high burden of access to medical services. Moreover, patients with GD required frequent healthcare utilization resulting in an annual direct cost (direct medical/non-medical costs) of $\$ 46,791$ per patient $(95 \% \mathrm{Cl}$ : $\$ 26,049, \$ 67,533)$; that is, $93.7 \%$ of total costs. In this study, the mean direct medical costs of $\$ 41,816$ per patient was about 66.5 times of the average health expenditure per patient (\$629) in China in 2018[50]. The direct medical costs included those for pharmaceutical $(\$ 29,908,59.9 \%)$, inpatient $(14.9 \%)$, and outpatient treatments (3.7\%). One study in Iran estimated the annual direct medical costs at \$20,758 in 2014 and identified drug costs as $95.2 \%(\$ 19,763)$ of direct medical costs[1]. These figures clearly show that the pharmaceutical cost encompasses most of the resources used by patients with GD. Recent research has also demonstrated that drug expenditures accounted for almost $90 \%$ of rare diseases' health expenditures[19]. 
Therefore, further efforts are needed to address the issue of pharmaceutical treatment costs holistically[51].

However, both the availability and affordability of orphan drugs[52] for the treatment of rare diseases in China are low[17]. Poor accessibility to drugs is the most problematic issue for patients with rare disease in China[53]. In this study, $89.8 \%$ of patients perceived the availability of therapeutic drugs to be problematic. Furthermore, $35.0 \%$ of patients who received pharmaceutical treatment could not take the medication as prescribed. These figures demonstrate poor availability of rare drugs. Several hindering factors contributing to the low availability of orphan drugs in China include the low market availability of orphan drugs in China[17, 54]. Compared with the earliest launch time globally, the average delay in the market authorization of orphan drugs for rare diseases in China was 7.7-9 years[17, 54]. Imiglucerase received China's marketing authorization in 2008[17]. On May 22, 2018, the Chinese Government officially included GD on the first list of rare diseases[55]. With a low availability of $<30 \%$ [17], many Chinese patients currently pay out-of-pocket for international treatments that are currently unapproved in China[56]. Second, lack of research and development and supply incentive policies for orphan drugs are possible reasons leading to low market availability[56]. Under a market-oriented economy, due to a small market share of orphan drugs, most pharmaceutical manufacturers are unwilling to invest in research and development on the production of orphan drugs without an incentive policy[17]. Third, low public hospital availability of orphan drugs is another major issue both for the patients[57] and the Chinese government. In this study, 31 (77.5\%) of patients reported purchasing medicine at pharmacies or overseas. Due to the unique market attributes (e.g., low market volume, low profit, low turnover rate, and high price) of orphan drugs, and as the reform of public hospitals in China stipulated (control the share of drug sales in total hospital revenue), hospitals have little incentive to stock and prescribe expensive orphan drugs[58]. Lastly, there are no public national or provincial networks for rare diseases or orphan drugs to share useful information about these diseases, e.g., treatment or supply information. Therefore, it is urgent to improve the availability of rare drugs, e.g., simplify the approval procedure for imported orphan drugs, increase research and development investment, formulate incentive policies, and establish information-sharing platforms.

Furthermore, to recoup research and development costs and for profit, orphan drug manufacturers often adopt a strategy of charging high prices[59]. Miglustat and imiglucerase, which are effective medications for treating GD, had annual costs of $\$ 116,800$ and $\$ 140,200$, respectively in 2004[60], and the expenditure share was $>3 \%$ of per capita GDP[16]. A study focusing on seven selected rare diseases found that the affordability of treatment was relatively poor, with the health expenditure for GD equivalent to 69.34 years per urban resident's income in 2014[16]. In this study, 49 (100\%) of patients reported the unaffordability of therapeutic drugs. A few cities/provinces are active in creating rare disease lists with a high reimbursement at $80 \%-95 \%[61]$. However, due to the restrictive reimbursement caps, even with $5 \%$ out-ofpocket expenses, few drugs could be afforded by high-income urban residents[62]. The out-of-pocket costs are still unaffordable for many patients. Therefore, the low affordability of orphan drugs may be closely associated with many factors, e.g., high drug prices, lack of insurance coverage, low reimbursement rates, and low-income levels for Chinese residents[17]. Several measures should be taken 
to improve the affordability of orphan drugs in China including: 1) formulating and implementing incentive policies $[59,63]$ to promote the development and supply of generic drugs, and to control the price of orphan drugs $[64,65] ; 2$ ) developing an orphan drug reimbursement system to increase insurance coverage; and 3) developing government-supported programs for patients with rare disease.

Due to the delayed diagnosis, unavailability, and unaffordability of costly drugs, $79.6 \%$ of 49 patients with GD felt poorly confident about future treatment. Moreover, the total social support, sleep quality, and quality of life scores for patients with GD/caregivers were significantly lower than those for normal healthy Chinese people. Thus, patients with GD experience limited access to health services, substantial costs, and low health-related quality of life [66].

\section{Limitations}

First, this study is limited primarily by the small sample size. Due to the rarity of GD, data collection was challenging. Second, families who voluntarily participate in the GD patient registry may represent a more compliant and motivated patient cohort in general. Thus, the findings may not be generalized to all. Thirdly, this study relied on responders' recall of health service utilization and the unit costs to capture a more inclusive set of cost components usually not included in billing data, such as traffic costs, formal care costs, and productivity loss to caregivers. To enhance the accuracy of the estimates reported, patients with GD and caregivers were asked to complete questions regarding the average consumption amount and costs per resource in the past year. However, recall bias may have led to errors. Lastly, utilization and corresponding costs from pharmaceutical use of prescription were not included in the survey. For pharmaceutical costs, we asked for the "annual purchase of imported/ domestic medicines," which could have resulted in an underestimation of this study's GD's financial burden. Hence, appraisal costs using data from health insurance is needed.

\section{Conclusions}

Patients with GD often encountered the frustrating experience of high misdiagnosis rate, long-delayed diagnosis, substantial costs, and deteriorated health-related quality of life in China. For patients with GD, a rapid, precise diagnostic tool for earlier and timely definitive diagnosis of GD is urgently needed. A more tailored medical insurance program that can effectively address the unmet health need of patients with GD should be designed. Measures targeting improving the availability and affordability of orphan drug needs to be developed holistically in China. Furthermore, newborn screening for disorders that meet the criteria for population screening with reliable diagnostic tools should be explored. Besides, enhancing doctors' ability in GD diagnosis and differential diagnosis, raising awareness of the early signs/symptoms or less severe manifestation to achieve earlier diagnosis and timely therapy of rare diseases, relieve caregivers' burden, and provide much needed social support are essential. This research can facilitate greater societal awareness of rare diseases, help policymakers develop appropriate intervention programs, and inform healthcare-focused support schemes and policies for patients and their families. 


\section{Methods}

\section{Development of the Survey}

An online retrospective survey of patients with GD and their caregivers was conducted for data collection. The inclusion criteria for patients were as follows: (i) a diagnosis of GD by a physician before the study; (ii) with a caregiver who was familiar with the whole treatment process of them; (iii) if the patient was under 15 , with a voluntary caregiver to help answer all the real information of them. The inclusion criteria for the caregivers included that he/she was: (i) the primary caregiver; (ii) was thoroughly familiar with the patient's disease; (iii) accompany patients every visit to the treatment; and (vi) was able to understand the content of the questionnaire.

The questionnaire, including the patient part and the caregiver part, is distributed simultaneously to eligible patients with GD and their caregivers. In the case of patients $<15$ years or patients who are dependent partly or on full-time care, patient part asked whether the patient can answer independently, and questions were set up in two ways (et al., "Birthdate of you" or "Birthdate of the patient"). The patient part was answered by themselves or with their caregivers' help if they can understand questions; if not, patient' information will be answered only by their caregivers.

\section{The patient part}

- Social-demographic characteristics

- Medical service utilization

- Cost of illness

- Social support (surveyed patients $>=5$ years)

- Sleep quality (surveyed patients $>=5$ years)

- The Short Form Health Survey (surveyed patients $>=5$ years)

\section{The caregiver part}

- Social-demographic characteristics

- Caregivers' perception of GD treatment

- Care burden

- Social support

- Sleep quality

- The Short Form Health Survey (SF-36)

The China Gaucher disease family exchange group (C-GDFEG) is currently the largest GD information exchange platform in China. From May to June 2018, we contacted a total of 98 families of patients with GD in C-GDFEG before conducting this survey. A total of eligible 51 (52.04\%) patients enrolled in this 
study. Both the patient part and the caregiver part completely answered was considered as a valid questionnaire. Of them, 49 (validity rate $96.08 \%$ ) patients with GD and their caregivers $(n=49)$ completed the questionnaire were included in this study. The contact details of the researchers were also sent to the participants for information and further communication.

\section{Questionnaire Design and Data Collection}

From the literature review, we identified key areas that were both important for the patients and families, and essential for the health authorities and service provision planning. The online self-administered questionnaire for the patients with GD, their caregivers, and their households comprised the following sections: (i) socio-demographics characteristics; (i) medical service utilization; (ii) cost of illness; (iii) social support; (iv) sleep quality; (v) care burden; and (vi) self-reported health (using SF-36).

\section{Definition and Measurements}

\section{Socio-demographic characteristics}

The patients' socio-demographic characteristics included age, sex, current residence, mean age at onset, disease duration, type of GD, family history of GD, and caregivers' number. Socio-demographic characteristics of the caregivers included the daily care time, experience of being a caregiver, stopped working because of patients' GD, change of weekly working scheme because of patient's GD, and members with chronic disease $>60 /<5$ years of age. Besides, whether living on minimum subsistence allowance or relatives' relief or not was also reported.

\section{Medical service utilization and caregivers' perception of GD treatment}

The medical service utilization data were collected in this study to assess patients' diagnosis and treatment status. Health service utilization covering the 12 months health service utilization of patients with GD surveyed by self-designed questions, including the following: (i) the original reason to see the doctors; (ii) symptom; (iii) types of medical institutions frequently visited; (iv) number of hospitals visited for GD diagnosis; ( $v$ ) total cost of GD diagnosis; (vi) length before the final GD diagnosis was confirmed; (vii) misdiagnoses; (viii) the number of misdiagnoses; (ix) therapy after GD diagnosis; (x) outpatient/inpatient visit for GD; (xi) traffic time; and (xii) surgery/pharmacologic therapy after GD diagnosis.

Additionally, caregivers' perceptions et al., "the availability and affordability of therapeutic drugs," "difficulties during GD treatment," "knowledge of GD," and "difficulties to get diagnosis information" were also investigated.

\section{Cost of illness}

We retrospectively evaluated the total cost of GD, comprising direct medical, direct non-medical, and indirect costs for individual patients and their families. Costs comprised the following components: Direct 
medical costs: (i) daily outpatient/inpatient treatment cost; (ii) laboratory and diagnostic costs; (iii) imported/domestic drugs' costs; (iv) formal care cost; (v) other direct outpatient/inpatient medical costs; Direct non-medical costs: (vi) outpatient/inpatient costs for accommodation/transportation/meals; (vii) artificial nutrition costs; (viii) other direct non-medical costs; and Indirect costs: (ix) daily lost wages of caregivers; $(x)$ annual indirect cost.

Respondents were also asked to recall the use of resources: (i) outpatient/inpatient visit frequencies (consultations) annually; (ii) the average days for each outpatient/inpatient visit; and (iii) total days of lost wages annually. The resources used were multiplied by the corresponding unit cost to estimate the annual cost per patient, and the monetary values of the unit prices were reported in USD (\$).

\section{Zarit Burden Inventory}

The subjective burden of the caregivers was measured by ZBI (22-item version), with item scores ranging from 0 (never) to 4 (nearly always). The total score ranges from 0 to 88 , and scores $<21$ correspond to little or no burden while scores $>61$ correspond to severe burden[67].

\section{Social Support Rating Scale}

SSRS comprise 10 items and includes three subscales: subjective support (4 items), objective support (3 items), and utilization of support ( 3 items). The total SSRS score ranges from 12 to 66 points, and higher scores indicate higher level of social support[68].

\section{Pittsburgh Sleep Quality Index}

Sleep quality of individuals in 1 month was measured using the PSQI (comprises 19 items and 7 dimensions), which includes subjective sleep quality, sleep onset latency, total sleep duration, sleep efficiency, sleep disturbances, use of sleep medication, and daytime dysfunction. The sub-total of the scores of each dimension ranges from 0 to 3 , and the maximum score is 21 . The cut-off score for PSQIdefined cases of poor sleep quality is $\geq 6$. A Chinese PSQI version has been validated with adequate reliability[69].

\section{The medical outcomes study 36-item Short Form}

Quality of life was measured by the SF-36 comprising 36 items including the physical and mental component scores[70]. Subscale scores are then transformed from the normal scale to a 0-100 standardized score scale, with higher scores indicating more positive health status and a better healthrelated quality of life.

\section{Statistical Analyses}

Descriptive analysis was conducted to evaluate the social demographic characteristics, the status of medical service utilization, cost of illness, and health-related quality of life. Continuous variables were presented as means $\pm S D$ s, and categorical variables were presented as absolute and relative frequencies. 
The 2.5 and $97.5 \%$ quantiles of the bootstrap distribution were used as the limits of the $95 \% \mathrm{Cl}$. All statisitical analyses were conducted using SAS software, version 9.4 (SAS Institute, North Carolina, US).

\section{Abbreviations}

C-GDFEG

China Gaucher disease family exchange group

$\mathrm{Cl}$

Confidence interval

DMC

Direct medical costs

DNMC

Direct non-medical costs

DMC outpatient

Direct medical costs of outpatient medical treatment

DMC inpatient

Direct medical costs of inpatient medical treatment

DMC pharmaceutical

Direct medical costs of pharmaceutical treatment

DMC medical tests

Direct medical costs of medical tests

DMC formal care

Direct medical costs of formal care

DMC other costs

Direct medical costs of other costs

GD

Gaucher disease.

GDP

gross domestic product

MCS

Mental Component Summary

PCS

Physical Component Summary

PSQI

Pittsburgh Sleep Quality Index

SD

standard deviation

SF-36

Medical Outcomes Study 36-item Short Form

SSRS 
Social Support Rating Scale

WHO

World Health Organization

ZBI

Zarit Burden Inventory

\section{Declarations}

\section{Ethics Approval and Consent to Participate}

This study was approved by the Ethics Committee of Harbin Medical University (No.HMUIRB20200001).

\section{Consent for Publication}

Yes

\section{Availability of Data and Materials}

Not applicable

\section{Competing Interests}

The authors declare that they have no competing interests.

\section{Funding}

The national social science fund of China (No.19AZD013)

\section{Authors' Contributions}

Writing - original draft by Xinye Qi; Conceptualization \& Methodology by Xinye Qi and Jiao Xu; Resource by Jiao Xu and Qunhong Wu; Writing - Review \& editing by Linghan Shan and Ye Li; Software by Yu Cui and Huan Liu; Formal analysis by Huan Liu and Kexin Wang; Project administration and Supervision by Lijun Gao and Zheng Kang; Funding acquisition \& Supervision by Qunhong Wu.

\section{Acknowledgments}

We wish to thank the patients and their families for participating in this study.

\section{References}

1. Davari M, Nabizadeh A, Kadivar M, Asl AA, Sarkheil P. Healthcare resource utilization and cost of care for Gaucher patients in Iran. J Diabetes Metab Disord [Internet]. 2019;18:127-32. Available from: $10.1007 /$ s40200-019-00399-x 
2. Serratrice C, Stirnemann J, Berrahal A, Belmatoug N, Camou F, Caillaud C, et al. A Cross-Sectional Retrospective Study of Non-Splenectomized and Never-Treated Patients with Type 1 Gaucher Disease. J Clin Med [Internet]. 2020;9:2343. Available from: 10.3390/jcm9082343

3. He J, Tang M, Zhang X, Chen D, Kang Q, Yang Y, et al. Incidence and prevalence of 121 rare diseases in China: Current status and challenges. Intractable Rare Dis Res [Internet]. 2019 [cited 2020 Dec 5];8:89-97. Available from: 10.5582/irdr.2019.01066

4. Yang Y, He J, Wang Y, Kang Q, Hu S. Study Feasibility of Multi-payment for Drugs for Rare Diseases --Taking Gaucher's Disease in Qingdao as Example. China Pharmacy [Internet]. [cited 2020 Nov 25];30:2593-6. Available from: http://wap.chinapharmacy.com/attached/wenjian/14/201910/18105336_2280.pdf

5. General Office. National Health Commission. Notice on publication of the Rare Diseases Diagnosis and Treatment Guide (2019) [Internet]. [cited 2020 Nov 19]. Available from: http://www.nhc.gov.cn/yzygj/s7659/201902/61d06b4916c348e0810ce1fceb844333.shtml

6. Chen M, Wang J. Gaucher disease: review of the literature. Arch Pathol Lab Med [Internet]. 2008;132:851-3. Available from: 10.1043/1543-2165(2008)132[851:GDROTL]2.0.CO;2

7. Cox TM, Drelichman G, Cravo R, Balwani M, Burrow TA, Martins AM, et al. Eliglustat compared with imiglucerase in patients with Gaucher's disease type 1 stabilised on enzyme replacement therapy: a phase 3, randomised, open-label, non-inferiority trial. Lancet [Internet]. 2015;385:2355-62. Available from: 10.1016/S0140-6736(14)61841-9

8. Statement for Rare Disease Day [Internet]. [cited 2020 Nov 28]. Available from: https://www.who.int/news/item/27-02-2018-statement-for-rare-disease-day

9. He J, Song P, Kang Q, Zhang X, Hu J, Yang Y, et al. Overview on social security system of rare diseases in China. Biosci Trends [Internet]. 2019;13:314-23. Available from:

10.5582/bst.2019.01209

10. Evans WR. Dare to think rare: diagnostic delay and rare diseases. Br J Gen Pract [Internet]. 2018 [cited 2020 Dec 3];68:224-5. Available from: 10.3399/bjgp18X695957

11. Accurate Diagnosis of Rare Diseases Remains Difficult Despite Strong Physician Interest [Internet]. Global Genes. 2014 [cited 2020 Dec 3]. Available from:

https://globalgenes.org/2014/03/06/accurate-diagnosis-of-rare-diseases-remains-difficult-despitestrong-physician-interest/

12. Motta I, Filocamo M, Poggiali E, Stroppiano M, Dragani A, Consonni D, et al. A multicentre observational study for early diagnosis of Gaucher disease in patients with Splenomegaly and/or Thrombocytopenia. Eur J Haematol [Internet]. 2016;96:352-9. Available from: 10.1111/ejh.12596

13. Gary SE, Ryan E, Steward AM, Sidransky E. Recent advances in the diagnosis and management of Gaucher disease. Expert Rev Endocrinol Metab [Internet]. 2018;13:107-18. Available from: 10.1080/17446651.2018.1445524

14. Dinur T, Istaiti M, Frydman D, Becker-Cohen M, Szer J, Zimran A, et al. Patient reported outcome measures in a large cohort of patients with type 1 Gaucher disease. Orphanet Journal of Rare 
Diseases [Internet]. 2020 [cited 2020 Dec 5];15:284. Available from: https://doi.org/10.1186/s13023020-01544-z

15. Jo C. Cost-of-illness studies: concepts, scopes, and methods. Clin Mol Hepatol [Internet]. 2014;20:327-37. Available from: 10.3350/cmh.2014.20.4.327

16. Xin X-X, Guan X-D, Shi L-W. Catastrophic expenditure and impoverishment of patients affected by 7 rare diseases in China. Orphanet J Rare Dis [Internet]. 2016;11:74. Available from: 10.1186/s13023016-0454-7

17. Gong S, Wang Y, Pan X, Zhang L, Huang R, Chen X, et al. The availability and affordability of orphan drugs for rare diseases in China. Orphanet J Rare Dis [Internet]. 2016;11:20. Available from: 10.1186/s13023-016-0392-4

18. Nalysnyk L, Hamed A, Hurwitz G, Simeone J, Rotella P. A Comprehensive Literature Review of the Burden of Gaucher Disease. Value Health [Internet]. 2014;17:A391. Available from: 10.1016/j.jval.2014.08.858

19. Hsu JC, Wu H-C, Feng W-C, Chou C-H, Lai EC-C, Lu CY. Disease and economic burden for rare diseases in Taiwan: A longitudinal study using Taiwan's National Health Insurance Research Database. PLoS One [Internet]. 2018;13:e0204206. Available from: 10.1371/journal.pone.0204206

20. Pierre-Etienne C, Anne-Sophie C, Ségolène A, Christian D. Diagnostic delay in rare diseases: a documented list of (296) rare diseases for which delayed diagnosis would be especially detrimental, based on the French situation. 2020 [cited 2020 Nov 27]; Available from: https://www.researchsquare.com/article/rs-32308/v1

21. Andrade-Campos M, Alfonso P, Irun P, Armstrong J, Calvo C, Dalmau J, et al. Diagnosis features of pediatric Gaucher disease patients in the era of enzymatic therapy, a national-base study from the Spanish Registry of Gaucher Disease. Orphanet J Rare Dis [Internet]. 2017;12:84. Available from: 10.1186/s13023-017-0627-z

22. Experiences of Rare Diseases: An Insight from Patients and Families (2010) [Internet]. Rare Disease UK; 2010 Dec p. 37. Available from: https://www.raredisease.org.uk/our-work/experiences-of-rarediseases-an-insight-from-patients-and-families-2010/

23. Thomas AS, Mehta AB, Hughes DA. Diagnosing Gaucher disease: an on-going need for increased awareness amongst haematologists. Blood Cells Mol Dis [Internet]. 2013;50:212-7. Available from: 10.1016/j.bcmd.2012.11.004

24. Mistry PK, Sadan S, Yang R, Yee J, Yang M. Consequences of diagnostic delays in type 1 Gaucher disease: the need for greater awareness among hematologists-oncologists and an opportunity for early diagnosis and intervention. Am J Hematol [Internet]. 2007;82:697-701. Available from: 10.1002/ajh.20908

25. Anderson M, Elliott EJ, Zurynski YA. Australian families living with rare disease: experiences of diagnosis, health services use and needs for psychosocial support. Orphanet J Rare Dis [Internet]. 2013;8:22. Available from: 10.1186/1750-1172-8-22 
26. Chopra M, Duan T. Rare genetic disease in China: a call to improve clinical services. Orphanet J Rare Dis [Internet]. 2015;10:140. Available from: 10.1186/s13023-015-0333-7

27. Xuefeng L, Xiangyu Z, Shu Z, Zijuan L, Jianyong Z, Jincheng Z, et al. Rare disease awareness and perspectives of physicians in China: a questionnaire-based study. 2020 [cited 2020 Dec 5]; Available from: 10.21203/rs.3.rs-65651/v1

28. Pomeranz K. EvaluatePharma ${ }^{\circledR}$ Orphan Drug Report 2019.pdf [Internet]. April p. 30. Available from: https://info.evaluate.com/rs/607-YGS-

364/images/EvaluatePharma\%20Orphan\%20Drug\%20Report\%202019.pdf

29. Mengyuan F, Xiaodong G, Guoxu W, Xiaoxiong X, Luwen S. Medical service utilisation, economic burden and health status of patients with rare diseases in China. J Chin Pharm [Internet]. 2018 [cited 2020 Nov 26];27:361-9. Available from: 10.5246/jcps.2018.05.037

30. Vandeborne L, van Overbeeke E, Dooms M, De Beleyr B, Huys I. Information needs of physicians regarding the diagnosis of rare diseases: a questionnaire-based study in Belgium. Orphanet Journal of Rare Diseases [Internet]. 2019 [cited 2020 Dec 5];14:99. Available from: https://doi.org/10.1186/s13023-019-1075-8

31. Melnikova I. Rare diseases and orphan drugs. Nature Reviews Drug Discovery [Internet]. 2012 [cited 2020 Dec 5];11:267-8. Available from: https://www.nature.com/articles/nrd3654

32. Zurynski Y, Deverell M, Dalkeith T, Johnson S, Christodoulou J, Leonard H, et al. Australian children living with rare diseases: experiences of diagnosis and perceived consequences of diagnostic delays. Orphanet Journal of Rare Diseases [Internet]. 2017 [cited 2020 Dec 5];12:68. Available from: https://doi.org/10.1186/s13023-017-0622-4

33. Kuiper G-A, Meijer OLM, Langereis EJ, Wijburg FA. Failure to shorten the diagnostic delay in two ultraorphan diseases (mucopolysaccharidosis types I and III): potential causes and implications. Orphanet J Rare Dis [Internet]. 2018;13:2. Available from: 10.1186/s13023-017-0733-y

34. Huang Y, Jia X, Tang C, Liu S, Sheng H, Zhao X, et al. High risk screening for Gaucher disease in patients with splenomegaly and/or thrombocytopenia in China: 55 cases identified. Clin Chim Acta [Internet]. 2020;506:22-7. Available from: 10.1016/j.cca.2020.03.016

35. Lei K, Zhao Y, Sun L, Liang H, Luo R, Sun X, et al. A pilot screening of high-risk Gaucher disease children using dried blood spot methods in Shandong province of China. Orphanet J Rare Dis [Internet]. 2018;13:48. Available from: 10.1186/s13023-018-0782-x

36. Mehta A, Belmatoug N, Bembi B, Deegan P, Elstein D, Göker-Alpan Ö, et al. Exploring the patient journey to diagnosis of Gaucher disease from the perspective of 212 patients with Gaucher disease and 16 Gaucher expert physicians. Mol Genet Metab [Internet]. 2017;122:122-9. Available from: 10.1016/j.ymgme.2017.08.002

37. Mehta A, Kuter DJ, Salek SS, Belmatoug N, Bembi B, Bright J, et al. Presenting signs and patient covariables in Gaucher disease: outcome of the Gaucher Earlier Diagnosis Consensus (GED-C) Delphi initiative. Intern Med J [Internet]. 2019;49:578-91. Available from: 10.1111/imj.14156 
38. Kaplan P, Baris H, De Meirleir L, Di Rocco M, El-Beshlawy A, Huemer M, et al. Revised recommendations for the management of Gaucher disease in children. Eur J Pediatr [Internet]. 2013 [cited 2020 Nov 27];172:447-58. Available from: https://doi.org/10.1007/s00431-012-1771-z

39. van Dussen L, Biegstraaten M, Dijkgraaf MG, Hollak CE. Modelling Gaucher disease progression: long-term enzyme replacement therapy reduces the incidence of splenectomy and bone complications. Orphanet J Rare Dis [Internet]. 2014;9:112. Available from: 10.1186/s13023-0140112-x

40. Zimran A, Belmatoug N, Bembi B, Deegan P, Elstein D, Fernandez-Sasso D, et al. Demographics and patient characteristics of 1209 patients with Gaucher disease: Descriptive analysis from the Gaucher Outcome Survey (GOS). Am J Hematol [Internet]. 2018;93:205-12. Available from: 10.1002/ajh.24957

41. Dinur T, Zimran A, Becker-Cohen M, Arkadir D, Cozma C, Hovakimyan M, et al. Long Term Follow-Up of 103 Untreated Adult Patients with Type 1 Gaucher Disease. J Clin Med [Internet]. 2019;8. Available from: $10.3390 / j \mathrm{jcm} 8101662$

42. Schlander M, Beck M. Expensive drugs for rare disorders: to treat or not to treat? The case of enzyme replacement therapy for mucopolysaccharidosis VI. Curr Med Res Opin [Internet]. 2009;25:1285-93. Available from: 10.1185/03007990902892633

43. Maaswinkel-Mooij P, Hollak C, van Eysden-Plaisier M, Prins M, Aerts H, Pöll R. The natural course of Gaucher disease in The Netherlands: Implications for monitoring of disease manifestations. J Inherit Metab Dis. 2000;23:77-82.

44. Weinreb NJ, Barbouth DS, Lee RE. Causes of death in 184 patients with type 1 Gaucher disease from the United States who were never treated with enzyme replacement therapy. Blood Cells Mol Dis [Internet]. 2018;68:211-7. Available from: 10.1016/j.bcmd.2016.10.002

45. Drelichman G, Ponce E, Basack N, Freigeiro D, Aversa L, Graciela E, et al. Clinical consequences of interrupting enzyme replacement therapy in children with type 1 Gaucher disease. J Pediatr [Internet]. 2007;151:197-201. Available from: 10.1016/j.jpeds.2007.02.057

46. Andrade-Campos MM, de Frutos LL, Cebolla JJ, Serrano-Gonzalo I, Medrano-Engay B, Roca-Espiau $\mathrm{M}$, et al. Identification of risk features for complication in Gaucher's disease patients: a machine learning analysis of the Spanish registry of Gaucher disease. Orphanet Journal of Rare Diseases [Internet]. 2020 [cited 2020 Dec 5];15:256. Available from: https://doi.org/10.1186/s13023-02001520-7

47. Puri RD, Kapoor S, Kishnani PS, Dalal A, Gupta N, Muranjan M, et al. Diagnosis and Management of Gaucher Disease in India - Consensus Guidelines of the Gaucher Disease Task Force of the Society for Indian Academy of Medical Genetics and the Indian Academy of Pediatrics. INDIAN PEDIATRICS. 2018;55:11.

48. National Data [Internet]. [cited 2020 Nov 17]. Available from: https://data.stats.gov.cn/english/ 49. van Dussen L, Biegstraaten M, Hollak CEM, Dijkgraaf MGW. Cost-effectiveness of enzyme replacement therapy for type 1 Gaucher disease. Orphanet J Rare Dis [Internet]. 2014;9:51. Available 
from: 10.1186/1750-1172-9-51

50. Statistical Bulletin of China's Health Development (2018) [Internet]. [cited 2020 Nov 18]. Available from:

http://www.nhc.gov.cn/guihuaxxs/s10748/201905/9b8d52727cf346049de8acce25ffcbd0.shtml

51. Cai X, Yang H, Genchev GZ, Lu H, Yu G. Analysis of economic burden and its associated factors of twenty-three rare diseases in Shanghai. Orphanet J Rare Dis [Internet]. 2019;14:233. Available from: 10.1186/s13023-019-1168-4

52. WHO | Negotiating prices of drugs for rare diseases [Internet]. WHO. [cited 2020 Dec 4]. Available from: http://www.who.int/bulletin/volumes/94/10/15-163519/en/

53. Yang $\mathrm{Y}, \mathrm{Kang} \mathrm{Q}, \mathrm{Hu} \mathrm{J}$, Kong $\mathrm{F}$, Tang $\mathrm{M}, \mathrm{He} \mathrm{J}$, et al. Accessibility of drugs for rare diseases in China: Policies and current situation. Intractable Rare Dis Res [Internet]. 2019 [cited 2020 Oct 19];8:80-8. Available from: 10.5582/irdr.2019.01068

54. Guan X, Zhang J, Man C, Ni B, Shi L. How Far Have We Come? Challenges to Orphan Drug Access in China, 2011-2017. Journal of Pharmaceutical Sciences [Internet]. 2019 [cited 2020 Dec 5];108:2199205. Available from: http://www.sciencedirect.com/science/article/pii/S0022354919300206

55. He J, Kang Q, Hu J, Song P, Jin C. China has officially released its first national list of rare diseases. Intractable \& rare diseases research. 2018;7:145-7.

56. Cheng A, Xie Z. Challenges in orphan drug development and regulatory policy in China. Orphanet Journal of Rare Diseases [Internet]. 2017 [cited 2020 Dec 5];12:13. Available from: https://doi.org/10.1186/s13023-017-0568-6

57. Dong D, Wang Y. Challenges of rare diseases in China. Lancet [Internet]. 2016;387:1906. Available from: 10.1016/S0140-6736(16)30418-4

58. Guan X, Qi L, Liu L. Controversy in public hospital reforms in China. The Lancet Global Health [Internet]. 2016 [cited 2020 Dec 5];4:e240. Available from: 10.1016/S2214-109X(16)00041-3

59. Picavet E, Morel T, Cassiman D, Simoens S. Shining a light in the black box of orphan drug pricing. Orphanet J Rare Dis [Internet]. 2014;9:62. Available from: 10.1186/1750-1172-9-62

60. McCabe C, Claxton K, Tsuchiya A. Orphan drugs and the NHS: should we value rarity? BMJ [Internet]. 2005 [cited 2020 Nov 28];331:1016-9. Available from: 10.1136/bmj.331.7523.1016

61. Huang R, Shao W. China Rare Disease Drug Accessibility Report [Internet]. Chinese Organization for Rase Disorders; 2019 p. 75. Available from:

https://www.iqvia.com/-/media/iqvia/pdfs/china/viewpoints/viewpoint-issue-42.pdf

62. Lucas F. Improving market access to rare disease therapies: A worldwide perspective with recommendations to the industry. Medicine Access @ Point of Care [Internet]. 2018 [cited 2020 Nov 26];2:2399202618810121. Available from: 10.1177/2399202618810121

63. Shi H, Huang L, Xu L. Current Situation and Prospect of Orphan Drugs in China. Value in Health [Internet]. 2016 [cited 2020 Nov 28];19:A883. Available from: 10.1016/j.jval.2016.08.295 
64. GPhA Report: Savings: \$1 Trillion Over 10 Years - Generic Drug Savings in the U.S. Journal of Pharmaceutical Health Services Research [Internet]. 2012 [cited 2020 Nov 26];3:229-36. Available from: https://doi.org/10.1111/jphs.12000

65. Godman B, Bennie M, Baumgärtel C, Sović-Brkičić L, Burkhardt T, Fürst J, et al. Essential to increase the use of generics in Europe to maintain comprehensive health care? Farmeconomia Health economics and therapeutic pathways [Internet]. 2012 [cited 2020 Nov 26];13:5-20. Available from: https://journals.seedmedicalpublishers.com/index.php/FE/article/view/312

66. Masek BJ, Sims KB, Bove CM, Korson MS, Short P, Norman DK. Quality of life assessment in adults with type 1 Gaucher disease. Qual Life Res [Internet]. 1999 [cited 2020 Dec 5];8:263-8. Available from: https://doi.org/10.1023/A:1008859420641

67. Tang B, Harary E, Kurzman R, Mould-Quevedo JF, Pan S, Yang J, et al. Clinical Characterization and the Caregiver Burden of Dementia in China. Value Health Reg Issues [Internet]. 2013;2:118-26. Available from: 10.1016/j.vhri.2013.02.010

68. Sun J, Sun R, Jiang Y, Chen X, Li Z, Ma Z, et al. The relationship between psychological health and social support: Evidence from physicians in China. PLOS ONE [Internet]. 2020 [cited 2020 Dec 5];15:e0228152. Available from: https://journals.plos.org/plosone/article? id=10.1371/journal.pone.0228152

69. Wang X, Wang X, Ma H. Manual of Mental Health Rating Scale (Updated Edition) [Internet]. Beijing: Chinese Journal of Mental Health; 1999 [cited 2020 Nov 20]. Available from: https://www.hanspub.org/reference/ReferencePapers.aspx?ReferencelD=87567

70. Li L, Wang HM, Shen Y. Chinese SF-36 Health Survey: translation, cultural adaptation, validation, and normalisation. J Epidemiol Community Health [Internet]. 2003;57:259-63. Available from: 10.1136/jech.57.4.259

71. Gengchun C. Optimizing the Terms of Mental Health Check About Adults in City of Our Country Study on the Degree of Social Sup port. Journal of Xi'an Institute of Physical Education [Internet]. 18:99-101. Available from: http://www.en.cnki.com.cn/Article_en/CJFDTOTALXATY200101036.htm

72. Xianchen L, Maoqin T, Lei H, Aizhen W, HongXin W, Guifang Z, et al. Reliability and validity of the Pittsburgh sleep quality index. Chinese journal of psychiatry [Internet]. 1996;29:103-7. Available from: http://en.cnki.com.cn/Article_en/CJFDTOTAL-ZHMA199602018.htm

73. Yanfang P, Chaozeng S, Huiqian H, Bin W, Guang L. Survey of health-related quality of life in population of 6 Chinese cities. Basic \& Clinical Medicine [Internet]. 2011;31:636-41. Available from: http://www.en.cnki.com.cn/Article_en/CJFDTOTAL-JCYL201106010.htm

\section{Figures}





IDNMC
四IC
ADMC Outpatient
ADMC Inpatient
MDMC Pharmaceutical lDMC Medical tests
IDMC Formal care
IDMC Other costs

\section{Figure 1}

The annual cost of illness proportion of Gaucher Disease (GD) in China. Notes: DNMC= Direct nonmedical costs; DMC = Direct medical costs; $D M C$ outpatient $=$ Direct medical costs of outpatient medical treatment; DMC Inpatient = Direct medical costs of inpatient medical treatment; DMC pharmaceutical = Direct medical costs of pharmaceutical treatment; DMC medical tests = Direct medical costs of medical tests; DMC formal care $=$ Direct medical costs of formal care; DMC other costs $=$ Direct medical costs of other costs.






\section{Figure 1}

The annual cost of illness proportion of Gaucher Disease (GD) in China. Notes: DNMC= Direct nonmedical costs; $\mathrm{DMC}=$ Direct medical costs; $\mathrm{DMC}$ outpatient $=$ Direct medical costs of outpatient medical treatment; DMC Inpatient $=$ Direct medical costs of inpatient medical treatment; DMC pharmaceutical $=$ Direct medical costs of pharmaceutical treatment; DMC medical tests $=$ Direct medical costs of medical tests; $\mathrm{DMC}$ formal care $=$ Direct medical costs of formal care; DMC other costs $=$ Direct medical costs of other costs.



回DNMC

MDMC Outpatient

ADMC Inpatient

IDMC Pharmaceutical 1DMC Medical tests

IDMC Formal care

IDMC Other costs

\section{Figure 1}

The annual cost of illness proportion of Gaucher Disease (GD) in China. Notes: DNMC= Direct nonmedical costs; $\mathrm{DMC}=$ Direct medical costs; $\mathrm{DMC}$ outpatient $=$ Direct medical costs of outpatient medical treatment; DMC Inpatient = Direct medical costs of inpatient medical treatment; DMC pharmaceutical = Direct medical costs of pharmaceutical treatment; $\mathrm{DMC}$ medical tests $=$ Direct medical costs of medical tests; $\mathrm{DMC}$ formal care $=$ Direct medical costs of formal care; DMC other costs $=$ Direct medical costs of other costs. 


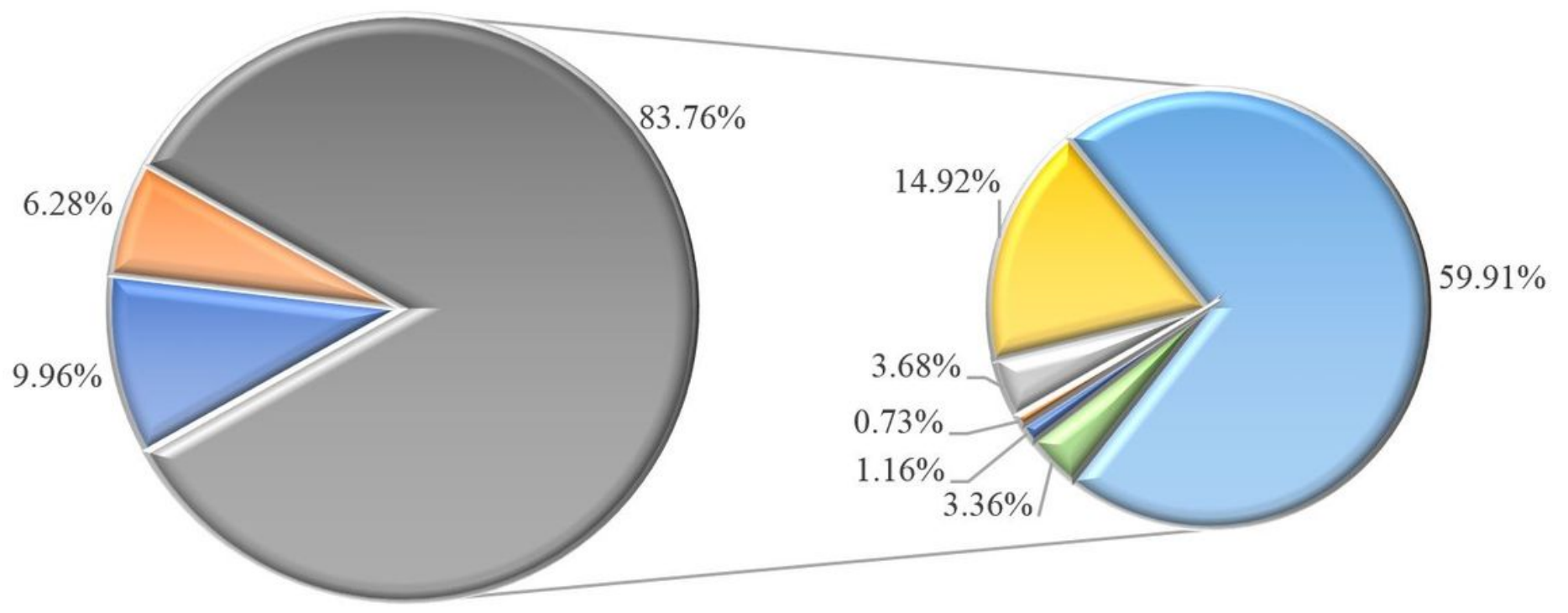
四DNMC
国IC
MDMC Outpatient
MDMC Inpatient
MDC Pharmaceutical laDC Medical tests
IDMC Formal care
IDMC Other costs

\section{Figure 1}

The annual cost of illness proportion of Gaucher Disease (GD) in China. Notes: DNMC= Direct nonmedical costs; DMC = Direct medical costs; $D M C$ outpatient $=$ Direct medical costs of outpatient medical treatment; DMC Inpatient = Direct medical costs of inpatient medical treatment; DMC pharmaceutical = Direct medical costs of pharmaceutical treatment; $\mathrm{DMC}$ medical tests $=$ Direct medical costs of medical tests; $\mathrm{DMC}$ formal care $=$ Direct medical costs of formal care; DMC other costs $=$ Direct medical costs of other costs.






\section{Figure 1}

The annual cost of illness proportion of Gaucher Disease (GD) in China. Notes: DNMC= Direct nonmedical costs; $\mathrm{DMC}=$ Direct medical costs; $\mathrm{DMC}$ outpatient $=$ Direct medical costs of outpatient medical treatment; DMC Inpatient = Direct medical costs of inpatient medical treatment; DMC pharmaceutical = Direct medical costs of pharmaceutical treatment; DMC medical tests = Direct medical costs of medical tests; DMC formal care $=$ Direct medical costs of formal care; DMC other costs $=$ Direct medical costs of other costs. 